EESTI RAKENDUSLINGVISTIKA ÜHINGU AASTARAAMAT 1 (2004), 35-51

\title{
ЗНАЧЕНИЕ АНАЛОГИИ ДЛЯ ЛИНГВИСТИКИ
}

\author{
ПИЛЛЕ ЭСЛОН
}

Аннотация. Для применения понятия аналогии в лингвистике существенными являются следующие моменты: 1) основой возникновения аналогий является психофизиологический механизм человека, что обусловливает номинализацию объектов и явлений на основе ассоциативной связи между ними и отражается в эволюции языка посредством динамики процессов грамматикализации и реграмматикализации; 2) антиномия открытости, асистемности, индивидуальности и упорядоченности, регулярности, системности, социальности языка опирается на его постоянную способность возобновляться и обогащать свой функциональный потенциал по аналогии; 3) аналогия обеспечивает стабильное неравновесие (самоорганизацию) системы языка; 4) аналогия раскрывает причинно обусловленные отношения между процессами определенного типа, особенно в плане установления межъязыковых корреляций в функционировании языковых единиц и категорий; 5) межъязыковая аналогия является методом познания и способом представления причинно обусловленных отношений между разными языками; 6) аналогия обладает объяснительной силой, являясь всеобщим и универсальным принципом научного познания; 7) проведение аналогий между разными научными теориями является возможностью их интеграции; 8) аналогия может служить методом анализа, классификации и способом описания функций языковых единиц; 9) аналогию можно применять как в исследовании одного языка, так и нескольких языков; как в плане диахронии, так и в плане синхронии; 10) установление аналогичных функций единиц разных языков является естественной опорой при изучении иностранных языков и для разработки методики их преподавания. ${ }^{1}$

В статье вниманию читателя предлагаются некоторые результаты исследования межъязыковых корреляций в выражении аспектуальных значений в русском и эстонском языках. Корреляции установлены путем применения аналогии как метода познания и интерпретации языкового материала.

Работа выполнена при поддержке госбюджетного проекта 0132493s03 “Eesti keelekeskkonna arengu analüüs, modelleerimine ja juhtimine". 
Ключевые слова: теория языка, методология научного исследования, основы классификации, семантика, аналогия, категории глагола, принципы сопоставления разносистемных языков, межъязыковые корреляции, аспектуальность, эстонский язык, русский язык

\section{1. Причинно обусловленные отношения и аналогия}

О роли аналогии в языке и лингвистике исследователи рассуждают со времен античности; начиная с В. Гумбольдта в аналогии видят один из факторов становления грамматических форм.

А. Мейе указывает, что грамматические формы могут приобрести свой статус путем двух разных процессов: посредством аналогии (образование новых форм по образцу какой-либо имеющейся формы) или же посредством грамматикализации (переход самостоятельного слова в разряд грамматических элементов языка) (Meillet 1926).

В трудах Ф. де Соссюра также указывается, что аналогия связана всегда с образцом, которому регулярно подражают, и поэтому роль аналогии заключается в упорядочении порождения единиц языка посредством регулярности и унифицированности этого процесса (Соссюр 1977: 195-196). Ф. де Соссюр подчеркивает, что аналогия является не фактом языкового изменения (цит. соч. С. 197-198), а фактом эволюции языка (цит. соч. С. 200 и след.). Именно в силу того, что язык постоянно возобновляется по аналогии, возможно его сохранение (цит. соч. С. 207). Развивая эти мысли, можно утверждать, что механизм порождения и функционирования языковых единиц на основе аналогии, с одной стороны, поддерживает постоянную открытость, известную асистемность и индивидуальность языка, а с другой стороны, является фактором создания его системности и упорядоченности. Подобные мысли созвучны с рассуждениями Э. С. Бауэра (Теоретическая биология. Будапешт, 1982), одного из основоположников теоретической биологии, который писал, что живой материи присуще стабильное неравновесие, являющееся залогом ее существования и развития (цит. по Valt 1986). В философии понятие стабильного неравновесия применяется по отношению к определению того, что такое закон (см. Друянов 1983: 128). Поскольку в диалектической логике закон определяется как инобытие случайностей, то 
признаками закона являются не только всеобщность, повторяемость, стабильность, сохраняемость, но и их относительность, что отражается в существовании необходимых связей между процессами определенного типа. Это положение подкрепляет нашу мысль о том, что всякая система возможна постольку, поскольку она по существу своему асистемна и именно поэтому способна находиться в постоянной готовности развиваться, функционально обогащаться (см. также Эслон 1994). Вместе с тем, стабильное неравновесие языковой системы затрудняет ее описание, в том числе и построение разного рода классификаций. Поэтому как процесс порождения, так и систематизация языковых единиц по признаку аналогичности выполняемых ими функций являются не просто всеобщим принципом существования и эволюции системы языка, но и методом ее познания, исследования и способом описания. В связи с этим понятие аналогии выходит за пределы своего узко-языкового понимания и становится достоянием методологии научного исследования, тем механизмом, с помощью которого можно раскрывать причинно обусловленные отношения в языке. Поскольку в сущности процесс сравнения языков опирается на поиск коррелятивных (системно обусловленных) связей между разными языками, то естественным является обращение к применению понятия аналогии как метода анализа и всеобщего методологического принципа научной интерпретации и интеграции полученного знания. Тем более, что аналогия основана на способности человека видеть подобие не только однопорядковых, но и разных по существу явлений (Курилович 1962), т. е. не только в стандартном и системном проявлении языка, но и в его нестандартности и асистемности. Следовательно, и Е. Курилович, по существу, пишет об аналогии как всеобщем принципе исследования и описания языка.

Такое же значение имеет понятие аналогии для Г. Дивальд. Она отмечает, что это понятие является своеобразным промежуточным звеном в исследовании языковых изменений и процесса (ре)грамматикализации, поскольку аналогией объясняется становление морфологических форм. Г. Дивальд считает, что в этом отношении понятие аналогии методологически более эффективно, чем структуралистское понятие оппозиции (Diewald 1997: 101 и след.). Общеизвестно, что не все в языке можно описать в виде противопоставлений. 
М. Эхала рассматривает вопрос аналогии тоже в плане методологии научного исследования, в связи с принципиальной возможностью интегрировать существующее теоретическое лингвистическое знание в единую концептуальную систему (Ehala 1996: 381 и след.). Залогом интегрированного подхода к языку, на взгляд М. Эхала, является осознание языка как самоорганизующей системы. Как на одно из наиболее ярких проявлений самоорганизующей сущности языка М. Эхала указывает на универсальный процесс грамматикализации, который наблюдается в истории развития всех языков. В основе грамматикализации лежат присущие человеку психофизиологические мыслительные процессы, имеющие сугубо индивидуальный характер, - это реанализ, базирующийся на метонимии, и аналогия, основывающаяся на метафоре. Грамматикализация происходит благодаря последовательному взаимодействию реанализа и аналогии. При этом под воздействием аналогии процесс грамматикализации все больше и больше углубляется (Ehala 1996: 382383). Из вышеизложенного можно сделать вывод, что аналогия является тем внутренним "рычагом" или механизмом, на котором основывается развитие языка как системы. Это понятие не только упорядочивает диахронические процессы, но также управляет синхроническими. И в этом отношении понятие аналогии является не просто внутриязыковым фактом, определяющим статус системы языка, оно становится важным всеобщим методологическим принципом научного объяснения и описания причинно обусловленных связей между процессами, которые происходят в “жизни” системы языка. Это очередное доказательство в пользу того, что понятие аналогии является одним из измерений, участвующих в создании интегрированного подхода к языку и к принципам его описания.

Раз аналогия является внутренним механизмом развития языка, основой причинно обусловленных отношений между единицами системы языка и межъязыковых связей, то принцип аналогии должен распространяться и на теорию языка. В частности, на типы научного объяснения. М. А. Шелякин (2002: 24-28) пишет, что причиной односторонности существующих теорий является отсутствие комплексного представления научного знания. Действительно, если в объекте лингвистического исследования естественным образом пересекаются разные сущностные характеристики языковой единицы, 
что определяет ее функциональный потенциал, то и анализ такого объекта, и его научное объяснение должны отличаться комплексной многомерностью. Вместе с тем, обычно лингвист обнаруживает аналогии на уровне языковых форм и их текстовых функций; гораздо реже - на уровне теоретической интерпретации, в научных объяснениях - в каузальном, телеологическом, системно-структурном, генетическом и др. Чтобы развивать теорию, необходимо как-то интегрировать частные типы научного объяснения. Одной из возможностей является проведение аналогий между ними. Это не будет “наложением” аналогий или же “подведением” под аналогии, потому что каждое из частных научных объяснений содержит в себе аналогию. Так, каузальный аспект научного объяснения объединяет явления на основе близости или сходности их причинной обусловленности; рациональный - на основе внутренней логики явлений; телеологический - на основе их близкой или сходной целесообразности; функциональный - опираясь на близость или сходство выполняемых ими функций и т. д. Как можно было убедиться, понятие аналогии включено в каждый из частных типов научного объяснения и поэтому аналогию действительно можно считать наиболее общим принципом научного объяснения, в котором интегрируются все указанные выше более частные типы - каузальное, рациональное, телеологическое, функциональное, системно-структурное и генетическое объяснения.

Вопрос применения понятия аналогии рассматривается также в прикладном аспекте (напр., Curtis, Reigeluth 1984). Э. Итконен (Itkonen 1992), ссылаясь на Р. Анттила (Analogy. The Hague: Mouton, 1977), полагает, что в процессе обучения иностранным языкам принцип аналогии должен иметь объяснительную силу. На наш взгляд, установление аналогии между объектами должно быть объяснено прежде всего каузально и телеологически. Дело в том, что возникновение аналогии, как отмечает Э. Итконен (Itkonen 1992: 42), присуще индуктивному типу мышления и поэтому естественно, что в проведении аналогий можно ошибиться. То же самое отмечается М. Эхала в связи с изучением второго языка, когда обучаемый, устанавливая ложную аналогию и опираясь на нее, тем самым начинает упрощать для себя трудности морфологических парадигм (Ehala 2000: 26 и след.). Это присуще человеку как натуре творческой. Если же 
аналогию основательно не объяснить с позиции каузальной, телеологической, функциональной, системно-структурной, генетической и др. , применяемых к межъязыковым отношениям и связям (к родному и изучаемому языку), то это может привести к ложному представлению об изучаемом языке. В результате действительное заменяется кажущимся, что приводит порою к трудно объяснимым ошибкам в употреблении языковых единиц, см. также подход Э. Муука (Muuk 2002).

Некоторые исследователи, изучающие применение метода аналогии в процессе обучения, основываются в своих теоретических рассуждениях на общем понимании аналогии как процесса сравнивания атрибутов двух домен: “--- analogy is defined as a similarity between concepts, a comparison of attributes between two domains ---" (Hulshof, Verloop 2002: 79). Далее приводится разграничение аналогий:

- аналогии, основывающиеся на метафоре (metaphorical ana$\operatorname{logy}$ ), или аналогии между разнопорядковыми доменами (fardomain analogy, или distant-analogy), например, как аналогия между бейсболом и математикой;

- аналогии, основывающиеся не на метафоре, или аналогии между соседствующими (однопорядковыми) доменами (neardomain), например, как аналогия между бейсболом и баскетболом.

По поводу последнего типа аналогии Э. Итконен уточняет, что аналогии между однопорядковыми объектами являются более естественными, конкретными и показывают, что между ними имеется по существу каузальная, то есть, - причинно обусловленная связь. Исследователь отмечает, что аналогию можно видеть также между одинаковыми объектами внутри одной категории объектов, например, между двумя велосипедами в классе велосипедов, но такая аналогия является тривиальной. Наконец, возможно проведение аналогии между самими аналогиями, что Э. Итконен называет метааналогией (Itkonen 1992: 40-41).

Таким образом, для применения понятия аналогии в лингвистике существенными являются следующие моменты:

1) основой возникновения аналогий является психофизиологический механизм человека, что обусловливает восприятие действительности, номинализацию объектов и явлений на 
основе ассоциативной связи между ними и отражается в эволюции языка посредством динамики процессов грамматикализации и реграмматикализации;

2) антиномия открытости, асистемности, индивидуальности и упорядоченности, регулярности, системности, социальности языка опирается на его постоянную способность возобновляться и обогащать свой функциональный потенциал по аналогии;

3) аналогия обеспечивает стабильное неравновесие (самоорганизацию) системы языка, что, вместе с тем, затрудняет ее исследование и описание;

4) аналогия раскрывает причинно обусловленные отношения (необходимые связи) между процессами определенного типа, особенно в плане установления межъязыковых корреляций в функционировании языковых единиц и категорий;

5) межъязыковая аналогия является методом познания и способом представления причинно обусловленных отношений между двумя и более языками;

6) аналогия обладает объяснительной силой; она является всеобщим и универсальным принципом научного объяснения, интегрирующим более конкретные - каузальное, рациональное, телеологическое, функциональное, системно-структурное и генетическое объяснения;

7) проведение аналогий между разными научными теориями является возможностью их интеграции;

8) аналогия может служить методом анализа, классификации и способом описания функций языковых единиц;

9) аналогию можно применять как в исследовании одного языка, так и нескольких языков; как в плане диахронии, так и в плане синхронии;

10) установление аналогичных функций единиц разных языков является естественной опорой при изучении иностранных языков и для разработки методики их преподавания.

Ниже вниманию читателя предлагаются некоторые результаты исследования межъязыковых корреляций в употреблении русского и эстонского глагола, которые были установлены путем применения аналогии как метода познания и интерпретации языкового материала. 


\section{2. Применение аналогии как метода познания и способа представления межъязыковых причинно обусловленных отношений}

Проведение межъязыковых аналогий опирается, во-первых, на единую функционально-семантическую основу - на понятие семантического поля или функционально-семантической категории (ФСК), как их понимает А. В. Бондарко (1983). Объектом настоящего исследования является ФСК аспектуальности. Во-вторых, с целью выявления межъязыковых корреляций на основе этой единой универсальной ФСК проводится сопоставительный анализ функций конкретных языковых единиц и категорий, служащих для выражения аспектуальных значений. В-третьих, при анализе и проведении межъязыковых аналогий в качестве второго измерения учитывается иерархичность построения языковой системы, а в качестве третьего измерения - характер установленных корреляций (межъязыковые эквиваленты, контрасты, расхождения и функциональные тождества - определение понятий и примеры (см. Эслон, Пихлак 1993: 3-5). В итоге можно получить многомерную классификацию, в которой интегрированы функциональный и системно-структурный подходы к сопоставлению языков. При этом к фактам диахронии обращаются лишь в том случае, если они имеют объяснительную силу. В целом же поиск аналогий проводится в синхронном плане.

Ниже рассматриваются аналогии, которые можно обнаружить в русском и эстонском языках при употреблении глагольных лексем, лексико-грамматических и грамматических категорий, а также синтаксических структур с целью выражения разных аспектуальных значений. Известно, что в русском языке грамматическим ядром поля аспектуальности является грамматическая категория вида, в то время как в эстонском языке говорится о субститутах русского вида (см. Эслон, Пихлак 1993, Эслон 2000, Vaiss 2004) - поэтому поле аспектуальности эстонского языка не имеет четко выраженного морфологического ядра. При передаче аспектуальных значений в эстонском языке мы имеем дело с определенными типами взаимодействия разноуровневых языковых средств и контекста. Следовательно, перед нами случай межъязыковой асимметрии, определяемый Ю. А. Пупыниным на материале одного языка (русского) как отсутствие взаимной 
проекции грамматических категорий (см. Пупынин 1990: 10), в нашем случае - как отсутствие взаимной межъязыковой проекции. Попутно отметим, что понятие проекции заимствовано из трудов В. Г. Адмони и определяется как способность грамматических форм взаимно спроецировать морфологические категории. Поэтому в форме следует видеть точку взаимного пересечения морфологических категорий (Пупынин 1990: 8). На наш взгляд, в этом внутриязыковом явлении кроется богатство функционального потенциала грамматических форм (Эслон 1991). Эвристическим методом его познания и исследования является сопоставление разных языков (о чем см. Eslon 2004a).

В результате поиска межъязыковых аналогий с учетом иерархичности (уровневости) языковой системы и содержательной характеристики установленных корреляций (межъязыковые эквиваленты, контрасты, расхождения и функциональные тождества), удалось выяснить те причинно обусловленные связи между русским и эстонским языками, которые присущи им в выражении аспектуальных значений (см. таблица 1).

В таблице 1 выделены языковые поуровневые корреляции между русским и эстонским языком при выражении семантики аспектуальности. Далее языковую соотносительность предстоит конкретизировать в рамках характера межъязыковых отношений.

В качестве межъязыковых эквивалентов рассматриваются лексикосемантический способ выражения аспектуального значения (исчезать / исчезнуть, умирать / умереть, кончать / кончить и terveks saama, kuulda võtma, maha kirjutama, ära andma, kokku lugema) и обстоятельственные распространители предложения (ситуация длительности действия: Он мылся долго и основательно - Ta pesi end kaua ja põhjalikult; ситуация завершенности действия: Oн быстро умылся Ta pesi end kiiresti puhtaks).

Как межъязыковые контрасты выделяются:

1) наличие морфологической категории вида в русском языке и ее отсутствие в эстонском;

2) наличие некоторых падежных форм $\boldsymbol{m} \boldsymbol{a}$-инфинитива в эстонском языке, которые выражают аспектуальные значения (о чем см. Эслон 1991); mas-форма употребляется в составе перифрастического глагола, т. е. грамматикализованного 
Таблица 1. Причинно обусловленные связи между русским и эстонским языками в выражении аспектуальных значений

Русский язык Эстонский язык

\section{1. Лексико-семантический уровень}

- Наличие аспектуального компо-

- Наличие аспектуального компонента нента значения в семантике значения в семантике глагола (типа глагола (типа исчезать / kaduma, surema, lõppema) исчезнуть, умирать / умереть, кончать / кончить)

- Аналогичное средство не выделяется

- Аналитические глаголы (типа terveks saama, kuulda võtma, maha kirjutama, ära andma, kokku lugema)

\section{2. Лексико-грамматический уровень}

- Наличие регулярного морфологического показателя предельности / непредельности глаголов (суффикс или префикс)

- Префиксальные и суффиксальные способы действия

- Наличие нерегулярного морфологического показателя предельности / непредельности (некоторые суффиксы)

- Суффиксальные способы действия синтетических глаголов; аналитические глаголы с адвербиальным ядром

- Функциональные видовые пары

- Неоппозитивное аспектуальное противопоставление синтетический / аналитический глагол

\section{3. Морфологический уровень}

- Наличие грамматической категории вида (оппозиция форм

- Отсутствие грамматической несовершенного и совершенного вида)

- Отсутствие аналогичного средства категории вида

- Видо-временные формы изъявительного наклонения

- Некоторые падежные формы $\boldsymbol{m a}$ инфинитива

- Грамматические формы времени изъявительного наклонения

\section{4. Синтаксический уровень}

- Отсутствие аналогичного

- Падеж объекта (номинатив, генитив, средства партитив)

- Обстоятельственные распростра-

- Обстоятельственные распространители нители

- Типология аспектуальных ситуаций

- Не разработана, однако по аналогии возможна 
семантико-синтаксического единства, указывающего на действие в его длительности (о чем см. Metslang 1994: 333); в русском языке инфинитив таких форм не имеет, ср. ситуация длительности: Ta on siin raamatuid lugemas $-O н$ здесь цитает книги; ситуация финальности: Vend tuli võistlemast - Брат возврашался с соревнования и Vend tuli võistlemast koju - Брат вернулся с соревнования и т. д.;

3) наличие номинативного, генитивного и партитивного объекта как синтаксического средства дифференциации аспектуальности (о чем см. Vaiss 2004: 145-184) и его отсутствие в русском языке, напр., Ma usaldan sind (партитив) - Я доверяю (настоящее НСВ) тебе; Ma usaldan sulle oma saladuse (генитив) - Я доверю (настоящее-будущее $\mathrm{CB}$ ) тебе свою тайну.

В качестве расхождений рассматриваются:

1) структурно-грамматическая дифференцированность аспектуальности синтетических и аналитических глаголов эстонского языка и грамматическое (суффиксально-префиксальное) разграничение видовых и акциональных значений в русском языке, напр., а) семантика непредельности + наличие суффикса, указывающего на длительность действия: русский НСВ (tervenета - выздоравливать, allkirjastama - подписывать и под.) и б) семантика предельности аналитического глагола: русский СВ (terveks saama - выздороветь, alla kirjutama подписать и под.);

2) выражение аспектуальных значений видо-временных форм русского глагола аналитическими и синтетическими формами времени в эстонском языке (о чем см. Эслон, Пихлак 1993: 76-108; Эслон 2000: 105-141); например, ситуация предельности: Ta on öelnud ja oma südant kergendanud (перфект) - Он сказал и облегчил (прошедшее СВ) свою душу; Talu oli mиитиnud (плюсквамперфект) kodutute varjupaigaks - Хутор превратился (прошедшее СВ) в убежище бездомных; ситуация непредельности: Ta ise on ka niisuguseid kirju kirjutanud (перфект) Он сам тоже писал (прошедшее НСВ) такие письма; Nõnda olime me arvanud (плюсквамперфект) - Так мы думали (прошедшее НСВ); ситуация реального действия в плане настоя- 


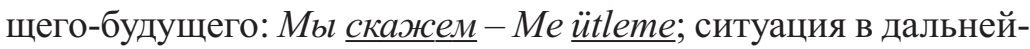
шей перспективе возможного будущего действия: Они будуm действовать - Nad hakkavad tegutsema (asuvad tegutsema). Форма настоящего времени эстонского синтетического глагола имеет широкий функциональный потенциал - от настоящего момента речи до ближайшего будущего - и поэтому функционирует аналогично с формой настоящего-будущего СВ в русском языке; такая же аналогия наблюдается между аналитической формой будущего времени в русском языке и эстонским семантико-синтаксическим единством с hakkama (см. Metslang 1994: 216-218);

3) соотносительность между функциональными (контекстуально обусловленными) видовыми парами русского языка (типа цеепляться / уиепиться, очнуться / приходить в чувство (в себя), сажать пятна / посадить пятно) (см. об этом Гак 1996: 62-71, Апресян 2004: 3-18) и неоппозитивным аспектуальным противопоставлением синтетический / аналитический глагол в эстонском языке типа tervenema / terveks saama, purustama / puruks tegema, võitlema / kätte võitma (см. об этом Эслон 2004b: 95-108, Eslon 2004a: 103-122);

4) расхождения в лексическом наполнении и синтаксическом характере аспектуальных ситуаций, определяющих выражение конкретных аспектуальных значений. Например, наличие лексических показателей постоянной повторяемости действия (типа kaua - долго, iga päev - каждый день, aastate pikku годами, pidevalt - постоянно, palju kordi - многократно и под.) соотносится с ситуацией непредельности, наличие показателей разовости действия (типа äkki- вдpyz, ükskord однажды, tänа - сегодня и под.) соотносится с предельностью ситуации. Вместе с тем нельзя сказать, будто между эстонским и русским языками при этом имеется полная соотносительность в употреблении лексики и грамматических средств. Это видно хотя бы на основе сравнения примеров с лексическими показателями интенсивности проявления действия или состояния. По логике вещей это лексическое средство должно дифференцировать непредельность ситуации. Вместе с тем по отношению к русскому языку все не так просто. Логично, что 
ПИЛЛЕ ЭСЛОН. ЗНАЧЕНИЕ АНАЛОГИИ ДЛЯ ЛИНГВИСТИКИ

в эстонском языке они неуместны в сочетании с аналитическими глаголами, содержащими семантику предельности, вместе с тем в русском переводе они в данном типе аспектуальной ситуации вполне допускаются: *Haige saab oluliselt (tunduvalt) terveks - Больной существенно (значительно) выздоровеет; *Haige sai oluliselt (tunduvalt) terveks - Больной сушественно (значительно) выздоровел; *Haige on oluliselt (tunduvalt) terveks saanud - Больной существенно (значиmельно) выздоровел. Логично также, что в сочетании с синтетическими глаголами эстонского языка, не содержащими семантику предельности, лексические показатели интенсивности проявления действия или состояния прямо напрашиваются. Вместе с тем в русском они включены в ситуацию предельности: Haige on oluliselt (tunduvalt) tervenепиd - Больной стал существенно (значительно) здоровее. На основе проанализированного случая можно сделать следующий вывод: если в эстонском языке лексические показатели интенсивности проявления действия или состояния дифференцируют прежде всего аспектуальную ситуацию непредельности, то в русском языке они подчеркивают степень проявления результата действия или степень полноты состояния, что непосредственно не характеризует аспектуальную ситуацию, а скорее всего является средством выражения оценочности, выделительности. Поскольку типы аспектуальных ситуаций и условия их лексического и грамматического наполнения на материале эстонского языка еще предстоит разработать, то пока рано говорить, какие причинно обусловленные межъязыковые связи здесь наблюдаются и на чем они основываются.

Приведенное выше распределение материала на основе характера межъязыковых связей является существенным не только в плане его теоретической интерпретации и научного обоснования, но и в плане преподавания второго языка.

Так, в межъязыковой эквивалентности просматривается универсальность человеческого мировосприятия и способа его представления языковыми средствами. Это тот пласт лексики и грамматики в разных языках, с которого следует начать изучение второго языка. В межъязыковой контрастности отражается специфическое для сопо- 
ставляемых языков. Ее следует воспринимать как аксиому и в учебном процессе сознательно выучить. В сферу межъязыковых расхождений включаются в основном скрытые от непосредственного наблюдения аналогии, которые возможно обнаружить в результате применения многомерного научного объяснения. Обычно это те языковые явления, которые находятся в стадии грамматикализации или лексикализации, развивают вариативность форм и функций, принимают новые функции, метафоризируются и т. д. Проведение ложных аналогий в этой области грозит в обучении труднообъяснимыми ошибками. Их предупреждению должна предшествовать серьезная работа по выявлению причинно обусловленных межъязыковых связей.

\section{Литература}

Апресян Ю. Д. 2004. О семантической непустоте и мотивированности глагольных лексических функций. - Вопросы языкознания 4, 3-18.

Бондарко А. В. 1983. Принципы функциональной грамматики и вопросы аспектологии. Ленинград: Наука.

Curtis, R. V. \& Reigeluth, C. M. 1984. The use of analogies in written text. - Instructional Science 13 (2), 99-117.

Diewald, G. 1997. Grammatikalisierung. Eine Einführung in Sein und Werden grammatischen Formen. - Germanistische Arbeitsberichten 36. Tübingen: Max Niemeyer Verlag.

Друянов Л. А. 1983. Категория “закон”. - Философские науки 4, 127-132.

Ehala, M. 1996. Integreeritud keeleteooria võimalikkusest tänapäeva keeleteaduses (II). - Keel ja Kirjandus 6, 375-384.

Ehala, M. 2000. Second language learners' impact on the structure of Estonian. Languages at Universities Today and Tomorrow. Ed. by K. Allikmets. Tartu, 20-32.

Эслон П. 1991. Роль внутрисистемных отношений в определении функционального потенциала языковых единиц и категорий (на материале русского и эстонского инфинитива). - Синтаксические и парадигматические связи языковых единиц и категорий (на материале разносистемных языков). Таллиннский пед. ун-т. Таллинн, 70-76.

Эслон П. \& Пихлак А. 1993. Вид и время. Таллиннский пед. ун-т. Таллинн.

Эслон П. 1994. Роль асимметрии, аналогии и нейтрализации в объяснении внутриязыковых процессов. - Вопросы современного состояния и исторического развития систем русского и болгарского языков. Шумен: Изд-во на ВПИ “Константин Преславски”, 50-71. 
Эслон П. 2000. Русский вид и его субституты в эстонском языке. - Функции и взаимодействие языковых единиц в тексте. Таллинн: TPÜ Kirjastus, 105141.

Eslon, P. 2004a. Mõningatest korrelatsioonidest vene ja eesti verbisüsteemis. - Toimiv keel II. Töid rakenduslingvistika alalt. Koost Helle Metslang, toim Maria-Maren Sepper, Jane Lepasaar. TPÜ eesti filoloogia osakonna toimetised 3. Tallinn: TPÜ Kirjastus, 103-122.

Эслон П. 2004b. О грамматикализации аналитических глаголов эстонского языка. - Linguistica Uralica 2, 95-108.

Гак В. Г. 1996. Функциональные видовые пары в русском языке. - Словарь. Грамматика. Текст. Сб. статей. Отв. ред. Ю. Н. Караулов, М. В. Ляпон. Москва: ИРЯ РАН, 62-71.

Hulshof, H. \& Verloop, N. 2002. The use of analogies in language teaching: representing the content of teachers' practical knowledge. - Journal of Curriculum Studies 34 (1), 77-90.

Itkonen, E. 1992. - 'Analogian’ käsite ja sen rooli kognitiivisessa kielitieteessa. Kielitieteen kentän kartoitusta. Turun yliopiston suomalaisen ja yleisen kielitieteen laitoksen julkaisuja 39. Turku, 39-49.

Курилович Е. 1962. О природе так называемых “аналогических" процессов. Е. Курилович. Очерки по лингвистике. Сб. статей. Москва: Изд-во иностр. лит., 92-121.

Meillet, A. 1926. L'évolution des formes grammaticales. - Linguistique historique et linguistique générale 2. Société de Linguistique Paris VIII, 130-148.

Metslang, H. 1994. Temporal Relations in the Predicate and the Grammatical System of Estonian and Finnish. - Oulun yliopiston suomen ja saamen kielen laitoksen tutkimusraportteja 39. Oulu.

Muuk, E. 2002. Häälikuseaduslikkus ja analoogilisus meie õigekeelsusnähtuste hindamismõõdupuuna. - T. Erelt. Eesti keelekorraldus. Tallinn: Eesti Keele Sihtasutus, 343-360.

Пупынин Ю. А. 1990. Функциональные аспекты грамматики русского языка: взаимосвязи грамматических категорий. Ленингр. гос. пед. ин-т им. А. И. Герцена. Ленинград.

Соссюр Ф. де 1977. Труды по языкознанию. Под ред. А. А. Холодовича. Москва: Прогресс.

Шелякин М. А. 2002. Язык и человек (К проблеме мотивированности языковой системы). - Труды по русской и славянской филологии. Лингвистика. Новая серия VII. Тарту.

Vaiss, N. 2004. Verbi aspektikategooria eesti ja vene keeles. - Eesti keel: võõrkeelest teiseks keeleks. Tallinn: TPÜ Kirjastus, 145-184.

Valt, L. 1986. Murranguaegadele mõeldes. - Eesti Loodus 7, 418-424. 


\title{
The significance of analogy in linguistics
}

\author{
PILLE ESLON
}

The present article describes the language means of the functional semantic field of aspectualism, comparing both Russian and Estonian. The analysis is based on the analogy as the most general principle of scientific perception that can also be used as a certain research method. It provides an opportunity to ascertain such interlanguage correlations that are hard to notice in case of a simple descriptive juxtaposition. Besides a common functional semantic subject (aspectualism), the principle of the hierarchy of language and character of correlations - equivalence, contrast, difference, functional identity have been taken as a basis for highlighting the correlations and their interpretation. It results in a multi-dimensional comparative model based on the principle of analogy.

The role of analogy in linguistics can be explained with the following:

1) The formation of analogies is a psychophysical process that is common to human being and helps him create connexions between the different associations that are created in comparing similar or different objects. This process is reflected in the development of the language by means of grammaticalization and regrammaticalization.

2) The development of a language system is based on openness, unsystematics, individuality and on the other hand arrangement, regularity, systematics, social antinomy, owing to that the constant analogy-based renewal of language becomes feasible.

3) Analogy ensures the stable unbalance of a language system (selforganization) that also complicates the description of language.

4) Analogy opens causal connections between certain processes and is expressed in interlanguage correlations.

5) Determination of interlanguage analogies is also both a means of perception and and the means of presenting causal relations.

6) Analogy is the most general principle of perception and an universal basis for the integration of the different classes of scientific explanation (causal, rational, teleological, functional, systematicstructural, genetic). 
7) The discovery of analogies between different theories is a ground for their integration and creation of new analogies.

8) Analogy can be used as a research method, as a basis to classification formation and in the description of a functional potential of language.

9) Analogy can be applied to both one and several languages, in both a synchroneous and a diachroneous plan.

Finding the functions of analogous linguistic expressions between the various languages and their description is a natural foundation for the upbuilding of foreign language teaching.

ПИЛЛЕ ЭСЛОН (1950) окончила Тартуский университет по специальности русский язык и литература. Кандидатскую диссертацию защитила в 1986 г. в Ленинградском государственном университете. Работает в Таллиннском педагогическом университете с 1976 г., начиная с 2002 г. старшим научным сотрудником кафедры общего и прикладного языкознания. Изучает вопросы функциональной грамматики русского языка, проблемы общего и сопоставительного языкознания, модальность, аспектуальность, инфинитив.

pille.eslon@tpu.ee

PILLE ESLON (1950) on lõpetanud Tartu Ülikooli vene keele ja kirjanduse erialal. Kaitses kandidaadikraadi 1986. aastal Leningradi Riiklikus Ülikoolis. Alates 1976. aastast töötab Tallinna Pedagoogikaülikoolis, 2002. aastast üld- ja rakenduskeeleteaduse õppetooli vanemteadurina. On uurinud vene keele funktsionaalset grammatikat, üld- ja kõrvutava keeleteaduse probleeme, modaalsust, aspektuaalsust, infinitiivi.

pille.eslon@tpu.ee 